\title{
Determinación del comportamiento hidráulico de los acuíferos del norte de la Orinoquia, Colombia*
}

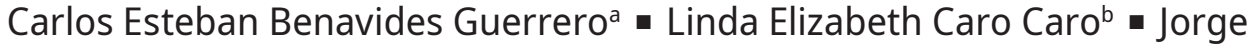 \\ Eliécer Mariño Martínez
}

\begin{abstract}
Resumen: Ia "sequía del Casanare" (2014-2015) prendió las alarmas sobre el desequilibrio que ocurre en algunas zonas de la Orinoquia, debido al inadecuado uso del suelo, la tala indiscriminada y la ausencia de las entidades reguladoras. Como consecuencia, se presenta creciente estrés hídrico, cuyo resultado es la muerte masiva de animales y la pérdida de cultivos, etc. Por tanto, se hacen necesarios estudios adicionales para entender la dinámica hídrica en el norte del Casanare, en las veredas de Caño Chiquito y Centro Gaitán, donde se presentaron los mayores estragos ambientales. Se investigaron los aspectos geológicos y geofísicos de la zona y se realizó la caracterización hidráulica, a partir de pruebas de bombeo, con las que se determinaron parámetros como la transmisividad, la capacidad específica, la conductividad hidráulica y el coeficiente de almacenamiento; con la finalidad de dar a conocer aproximaciones de las condiciones hidrogeológicas de la zona. La geología está determinada por el ambiente de depositación de abanico aluvial influenciado por
\end{abstract}

* Artículo de investigación.

a Egresado de la Escuela de Ingeniería Geológica de la UPTC. Ingeniero Geólogo, cofundador del capítulo estudiantil de hidrogeología de la uptc (CEH-UPTC_Sog), donde ejerció como vicepresidente en 2016-2017. Actualmente se desempeña como ingeniero consultor independiente. UPTC, Bogotá, Colombia. Correo electrónico: carlos.benavides01@uptc.edu.co ORCID: https://orcid.org/0000-0003-0661-8146

b Ingeniera geóloga de la Escuela de Ingeniería Geológica de la UPTC. Miembro del capítulo estudiantil de hidrogeología de la UPTC (CEH-UPTC_Sog), ejerció como auxiliar de ingeniería, en convenio con Colciencias y la UPTC, en el proyecto de investigación "Convenio Colciencias-UPTC modelo hidrogeológico conceptual e isotópico de la sabana estacional de paz de Ariporo, Casanare, Colombia" y como auxiliar de ingeniería en la "elaboración del estudio de impacto ambiental del área de perforación exploratoria Cor-15 a realizarse en los municipios de Tasco, Corrales, Busbanza y Betéitiva, de acuerdo con los términos de referencia M-Mina-01 de la Anla". UPTC, Bogotá, Colombia. Correo electrónico: linda.caro@uptc.edu.co ORCID: https:// orcid.org/0000-0001-6216-4703

c Profesor de Ingeniería Geológica e Ingeniero Geólogo de la UPTC. Magíster en Geología de la Universidad de Brigham Young (Utah). Doctor en Geología de la Universidad de Illinois (EE. UU.). Ha sido director de Investigaciones (Cifas) de la UPTC -Sede Sogamoso. Es representante de la UPTC ante la Red Nacional de Laboratorios de Geociencias (RNLG) y concejero ante el Concejo de Geociencias de Colciencias. Su investigación se enfoca en hidrocarburos no convencionales, flujo regional y estratigrafía. En la actualidad está a cargo del Laboratorio de Hidrocarburos no Convencionales de la UPTC. Correo electrónico: jorge. marino@uptc.edu.co ORCID: https://orcid.org/0000-0001-5105-2095 
corrientes fluviales en la sección media y depósitos eólicos en la zona más alejada del piedemonte, información corroborada por las secciones de tomografías. De acuerdo con las pruebas de bombeo, se estableció que se encuentran acuíferos de productividad que va de muy pobre a buena, de acuerdo con los valores de transmisividad, con permeabilidades que oscilan de muy bajas a bajas, en relación con los valores de conductividad hidráulica; además, según su capacidad específica, los acuíferos varían en su extensión y continuidad, cuando se trata de acuíferos locales (depósitos cuaternarios) a regionales (Formación Guayabo).

Palabras clave: acuíferos superficiales; aguas subterráneas; cambio climático; estiaje; hidráulica; Orinoquia; pruebas de bombeo.

\section{Recibido: 26/03/2020 Aceptado: 13/12/2020 Disponible en línea: 23/07/2021}

Cómo citar: C. E. Benavides Guerrero, L. E. Caro Caro, y J. E. Mariño Martínez, «Determinación del comportamiento hidráulico de los acuíferos del norte de la Orinoquia, Colombia», Cien.Ing. Neogranadina, vol. 31, n. ${ }^{\circ}$ 1, pp. 109-127, jul. 2021.

\section{Determination of the Hydraulic Behavior of Aquifers in Northern Orinoquia, Colombia}

Abstract: The "Casanare Drought" (2014-2015) triggered alarms on the imbalance taking place in some areas of the Orinoquia region, due to inadequate soil use, indiscriminate felling, and the absence of regulatory agencies. As a consequence, there is increasing water stress, resulting in the mass death of animals and loss of crops, among other phenomena. Further studies are needed to understand the water dynamics in northern Casanare, especially in the small villages of Caño Chiquito and Centro Gaitán, where the greatest environmental damage occurred. The geological and geophysical aspects of the area were studied along with a hydraulic characterization, based on pumping tests, which determined parameters such as transmissivity, specific capacity, hydraulic conductivity and storage coefficient. All of this was conducted to know the hydrogeological conditions of the zone. The geology of the area is determined by the environment of deposition of alluvial fan influenced by river currents in the middle section, and wind deposits in the farthest area of the foothills. This information is corroborated by the tomographic sections. As a result of the pumping tests, it was possible to determine that there are aquifers with a wide productivity range goes from very poor to good, according to the transmissivity values, with permeabilities that range from very low to low, in relation to the values of hydraulic conductivity. In addition, according to their specific capacity, aquifers vary in extension and continuity, when they are local aquifers (quaternary deposits) to regional aquifers (Guayabo formation).

Keywords: Surface aquifers, groundwater, climate change, estimating, hydraulic, Orinoquia, pumping tests. 


\section{Introducción}

El agua es esencial en la supervivencia y el desarrollo humano. Pero, a pesar de su abundancia, el agua potable es muy escasa. Con el pasar de los años, el líquido se ha convertido en un recurso limitado, hecho que deriva en una problemática social y medioambiental, especialmente para las poblaciones más apartadas de las grandes urbes, desprovistas de acueductos y fuentes de abastecimiento cercano.

Un ejemplo de esta problemática se evidenció en los Llanos Orientales de Colombia en la llamada "sequía del Casanare" [1], donde el desequilibrio ambiental, producto del cambio climático, ha provocado la prolongación de las temporadas de estiaje que, sumado al inadecuado uso del suelo, la tala indiscriminada y la escasa presencia de entidades reguladoras, han desencadenado una crisis por el recurso. Esto último se debe al estrés hídrico que ha venido acrecentándose, cuya consecuencia es la muerte masiva de animales, la pérdida de cultivos, el aumento de la degradación, la acidez y la erosión del suelo apto para el cultivo y la ganadería, de los cuales deriva el sustento de la población del lugar.

Actualmente, no son muchos los estudios hidrogeológicos adelantados en el área de nuestro interés, de modo que, a continuación, se mencionan los más relevantes.

La cartografía geológica del área adelantada por el Servicio Geológico Colombiano (sGC) en las planchas Guachiría y Paz de Ariporo [2], [3] indica que los depósitos superficiales son cuaternarios de origen fluvial, hacia el occidente de Paz de Ariporo, y eólicos hacia el oriente.
El estudio del Plan Básico de Ordenamiento Territorial (вот) del municipio de Paz de Ariporo encontró, primero, que los depósitos cuaternarios superficiales son acuíferos libres y, segundo, que a mayores profundidades se encuentran rocas consolidadas, con características de acuíferos semiconfinados y confinados [4]. A pesar de que, en el вот, los acuíferos se clasificaron, no se hicieron pruebas de pozo para determinar las características hidráulicas.

Más recientemente, el sGC (2018) realizó un estudio hidrogeológico en los alrededores de Yopal, que incluyó un balance hídrico con bajos índices de infiltración y pruebas de pozo para determinar transmisividad y capacidad específica. Sin embargo, estas pruebas se limitaron al área de Yopal, donde las condiciones no representan la totalidad del comportamiento hidrogeológico de los Llanos Orientales [5].

A pesar de los trabajos realizados, se hacen necesarios estudios adicionales para entender mejor el comportamiento hidráulico en el norte del Casanare, más concretamente en la cuenca del río Guachiría, que abarca los caseríos de Caño Chiquito y Centro Gaitán, donde se presentaron los mayores estragos ambientales en el departamento (figura 1). Para ello es necesario utilizar métodos no invasivos de exploración del subsuelo, que sean asequibles por las condiciones y extensión de la zona, como la geoeléctrica (tomografías y sondeos eléctricos verticales -SEv), que sirve para entender mejor la disposición en profundidad de los depósitos cuaternarios y su influencia en la circulación natural del agua. 


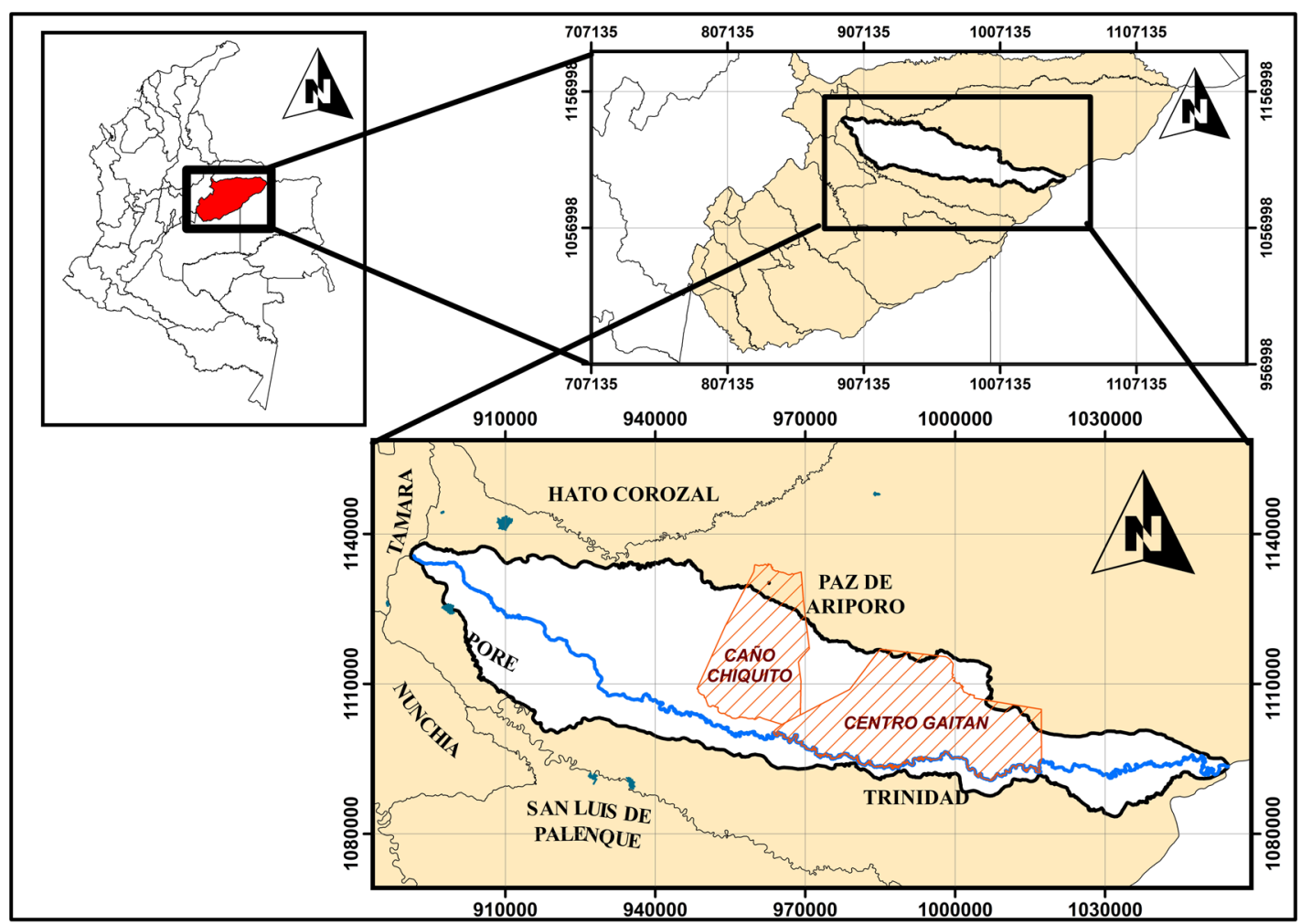

Figura 1. Localización de la cuenca del río Guachiría.

Fuente: elaboración propia.

La basta información sísmica existente en los Llanos Orientales no fue de utilidad, ya que los primeros metros nunca son confiables, presentan mucho ruido y distorsión debido al método de inducción de ondas al subsuelo. Esta información es determinante, puesto que en los primeros 100 metros es donde se encuentran los pozos de aguas subterráneas que abastecen a la población. De igual forma, es fundamental elaborar pruebas de pozo con la finalidad de conocer las características hidráulicas de los acuíferos, especialmente ahora que los problemas de sequía se han acentuado.

Debido a los periodos de estiaje más recientes (2014-2015), se han buscado alternativas mediante la prospección y exploración de fuentes de abastecimiento de aguas subterráneas, por medio de pozos profundos en los acuíferos superficiales de las llanuras, especialmente en los depósitos cuaternarios. Pese a ello, la falta de conocimientos técnicos sobre las propiedades hidráulicas de estos acuíferos hace evidente la necesidad de estos estudios.
La finalidad de la presentación de esta información es proporcionar bases técnicas que ayuden a entender el comportamiento y la ocurrencia del agua subterránea, para el adecuado uso de estas fuentes hídricas. Esto, debido a que las variables determinadas mediante pruebas de bombeo como la transmisividad y el coeficiente de almacenamiento sirven como indicadores de la productividad, factores que dependen de la litología y el espesor saturado. Del mismo modo, el volumen de agua utilizable podría cuantificarse con el producto de las dimensiones del acuífero (superficie y espesor) por el coeficiente de almacenamiento. Este es un valor confiable, teniendo las dimensiones reales o más aproximadas del acuífero que se analice.

\section{Marco geológico e hidrogeológico}

El conocimiento de la geología de la cuenca del río Guachiría es determinante para entender el sistema hidrogeológico del área. Esta región abarca la 
depresión estructural con dirección NE [6] que, a su vez, comprende unidades que influyen geomorfológicamente la cuenca del río Guachiría, caracterizada por patrones de drenaje meándricos y trenzados, debido al cambio de la pendiente y a la litología sobre la cual circula el agua.

Inicialmente, se observan gravas hacia la parte más alta de la cuenca en la zona del piedemonte $\mathrm{y}$, a medida que va alejándose, disminuyen su tamaño, siguiendo la secuencia típica de un abanico aluvial, debido al cambio de pendiente entre el piedemonte y la zona de los llanos. Posteriormente, sobre la región media de la cuenca, se encuentran materiales arenosos y limoarcillosos, producto de los flujos asociados a ríos trenzados con corrientes múltiples, que depositan barras laterales y longitudinales. Hacia la parte baja o llanura de inundación, los ríos son meándricos con corrientes de alta sinuosidad, por la poca pendiente del terreno, en cuyos meandros abandonados se depositan arcillas y material vegetal.

En general, los cursos de agua presentan baja energía, capacidad erosiva y capacidad de carga de sedimento, que corresponden a arenas y partículas finas que, a su paso, van creando diferentes geoformas como barras laterales, terrazas y llanuras aluviales. En la figura 2, puede observarse un diagrama esquemático en dirección NW-SE, desde el piedemonte hasta la llanura de inundación de la disposición de las litologías de los depósitos cuaternarios que pueden encontrarse en la cuenca del río Guachiría.

\section{LEYENDA}

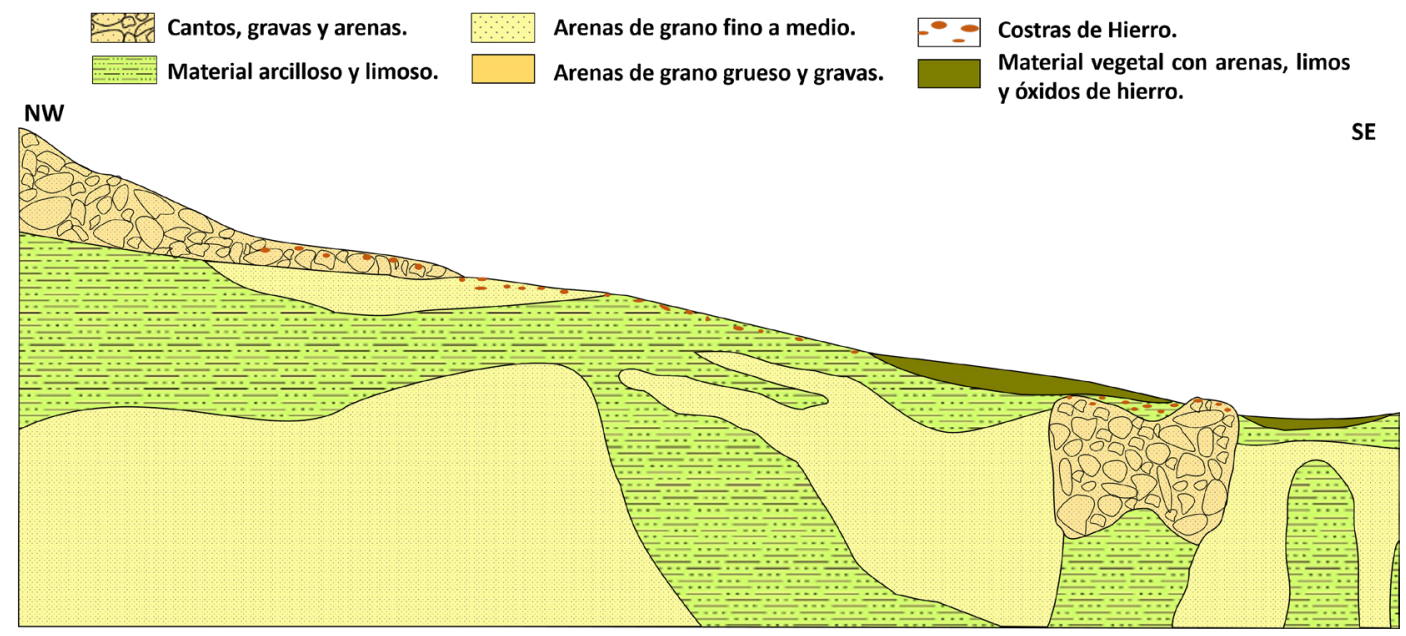

Figura 2. Esquematización litológica de la cuenca del río Guachiría de acuerdo con los SEV.

Fuente: elaboración propia.

Las formaciones terciarias de la cuenca están cubiertas por depósitos cuaternarios de origen fluvial y eólico [2]. La estratigrafía superficial inicia con los depósitos cuaternarios, conformados por (1) depósitos de planicies aluviales — compuestos por gravas, arcillas, limos arenosos y niveles de óxidos de hierro-; (2) depósitos eólicos - limos, arenas cuarzosas medias a muy finas-y (3) depósitos aluviales recientes dejados por las corrientes hídricas hasta la actualidad.
Los depósitos cuaternarios arenosos constituyen los acuíferos superficiales libres. A los cuaternarios, infrayacen unidades de edad neógena de ambiente continental, de las cuales la más superficial es la Formación Guayabo, compuesta de arena fina a media, fragmentos líticos, algunos niveles de conglomerados con secuencias de arcillolitas y limolitas. Dicha formación, predominantemente arenosa, constituye los acuíferos confinados de los pozos más profundos, como los existentes en los caseríos de Caño Chiquito y Centro Gaitán. 


\section{Materiales y métodos}

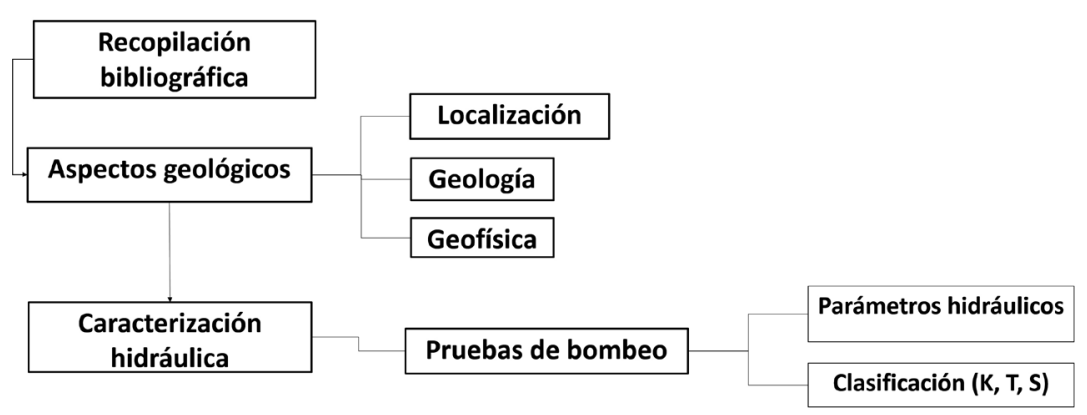

Figura 3. Metodología de trabajo.

Fuente: elaboración propia.

Los estudios preliminares incluyeron la recopilación y revisión de la cartografía geológica y estudios relacionados de la cuenca del río Guachiría y sus inmediaciones en los municipios de Paz de Ariporo, La Trinidad, Pore y Hato Corozal. Posteriormente, se determinó la resistividad eléctrica de las rocas del subsuelo (tomografías y SEv), para conocer las litologías de los acuíferos a profundidad, en las cercanías a los sitios donde se realizaron las pruebas de pozo. Asimismo, logró recopilarse información geoeléctrica, para conocer a profundidad la disposición geológica de los depósitos cuaternarios, sobre los cuales se encontraban pozos de extracción de agua.

Finalmente, se realizó la caracterización hidráulica, a partir de pruebas de bombeo, para determinar los parámetros hidráulicos y los diferentes tipos de acuíferos que pueden encontrarse en la parte norte de la Orinoquia colombiana (figura 4). Todo ello, se hizo con la finalidad de estimar el potencial de las rocas y depósitos presentes, así como sus propiedades para almacenar y transmitir agua.

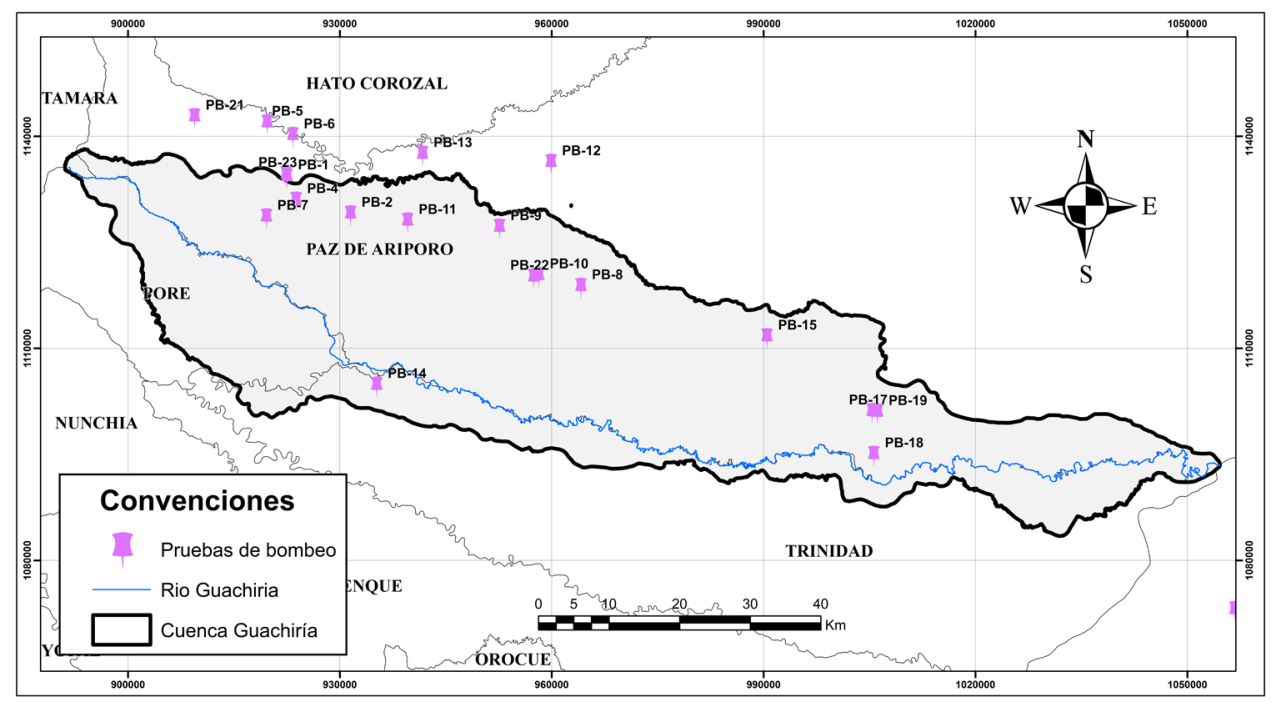

Figura 4. Localización de pruebas de bombeo realizadas por los autores y reinterpretadas o recopiladas de la literatura.

Fuente: elaboración propia. 
En el desarrollo del estudio, fue necesario delimitar el área de trabajo de la cuenca del río Guachiría, debido a que en ella es donde más información pudo obtenerse; también porque la zona de estudio está atravesada por una vía principal de circulación, el carreteable que de Paz de Ariporo conduce a las veredas Caño Chiquito y Centro Gaitán, dos de las veredas más afectadas por la sequía de 20142015. Además, esta cuenca es un buen ejemplo de los diferentes ambientes que pueden encontrarse en los Llanos Orientales cercanos al piedemonte.

Las pruebas de pozo se desarrollaron, primero, en agosto de 2017, en las veredas Labrancitas, Las Gaviotas y Caño Chiquito; segundo, en enero y febrero de 2018, en la veredas Caño Chiquito, Labrancitas, Brisas del Bebedero y en la cabecera municipal de Paz de Ariporo, Casanare (figura 4).

Para las pruebas de bombeo, se usaron (1) bombas eléctricas, en su mayoría, para la extracción de agua y (2) una sonda eléctrica marca Heron de alarma luminosa y sonora con precisión al milímetro, para la medida del descenso del agua. Además, se realizaron aforos volumétricos, con el fin de encontrar los caudales de cada una, los cuales tuvieron una duración diferente.

Al momento de realizar las pruebas, se observaron características que sirvieron para determinar el comportamiento de los acuíferos, tales como el abatimiento y la rapidez de recuperación, información que permitió conocer los parámetros hidráulicos de cada fuente de abastecimiento y realizar una correcta interpolación de cada punto de muestreo. De esta forma, se obtuvo información acerca de las condiciones locales del flujo de aguas subterráneas en los depósitos cuaternarios.

Los pozos empleados en estas pruebas permanecieron sin bombear varias horas antes del inicio de las pruebas de bombeo. Esto se hizo con el fin de determinar su nivel estático. Al respecto, cabe resaltar que no se contó con pozos de observación, ya que no existen en la zona.

Adicionalmente, se recopiló información de estudios de impacto ambiental (EIA) en resoluciones de la Agencia Nacional de Licencias Ambientales (Anla), pertenecientes a los bloques de exploración petrolera en el municipio de $\mathrm{Paz}$ de Ariporo. Asimismo, se realizó la reinterpretación de cuatro pruebas de bombeo (pozo Xfía, pozo Finca Taparas, Dorotea A1 y Dorotea B2), elaboradas en los estudios mencionados.

Una vez obtenidos los valores en campo, se realizó el trabajo de laboratorio, donde se utilizaron dos softwares: Aquifer test ${ }^{1}$ (figura 5) y R-Studio ${ }^{2}$, con el paquete Pumping test (figura 6). Con estas herramientas, se interpretaron los parámetros hidráulicos (transmisividad, capacidad específica, conductividad hidráulica y coeficiente de almacenamiento), para determinar las características de los diferentes tipos de acuíferos, de los cuales está extrayéndose agua en la actualidad y son fuente de abastecimiento de la población local.

El cálculo de las características hidráulicas sería relativamente fácil si se conociera con precisión el sistema acuífero. Por lo general, este no es el caso, por lo que interpretar una prueba de bombeo es, principalmente, una cuestión de identificar un sistema desconocido. La identificación del sistema se basa en modelos (diagramas de diagnóstico), resultado de graficar abatimiento frente a tiempo, cuyas características se supone que representan las características del sistema acuífero real [7]. Para la estimación de parámetros hidráulicos, la herramienta Aquifer Test se basa en el método simple para la minimización de funciones, mientras que el paquete Pumping Test estima parámetros usando regresión no-lineal.

De acuerdo con el comportamiento hidráulico obtenido en cada pozo, se analizaron los resultados por métodos establecidos para cada tipo de acuífero, clasificados de acuerdo con cada una de las gráficas obtenidas y los datos de coeficiente de almacenamiento, ya que no se contaba con la geología a detalle en cada pozo. Para acuíferos confinados generalmente se usa el método de Theis [8], en el cual se considera que el caudal de descarga de un pozo ubicado en un acuífero confinado es

1 Aquifer test es herramienta computacional de Waterloo Hydrogeologic Inc., que forma parte de Schlumberger Water Services (sws), para la gestión de datos ambientales, análisis y simulación del comportamiento del agua subterránea.

2 Es una librería de uso libre, ejecutada en el lenguaje de programación para estadística R. Fue desarrollada con fines académicos por Oscar García de la UPTC y usa el análisis moderno de pruebas de pozo. 
directamente proporcional a los abatimientos por el coeficiente de almacenamiento; esto, sumado al área de almacenamiento. En este método, se asume que el acuífero es homogéneo y de espesor uniforme en el área de influencia de la prueba, de extensión infinita, confinado y sin fugas.

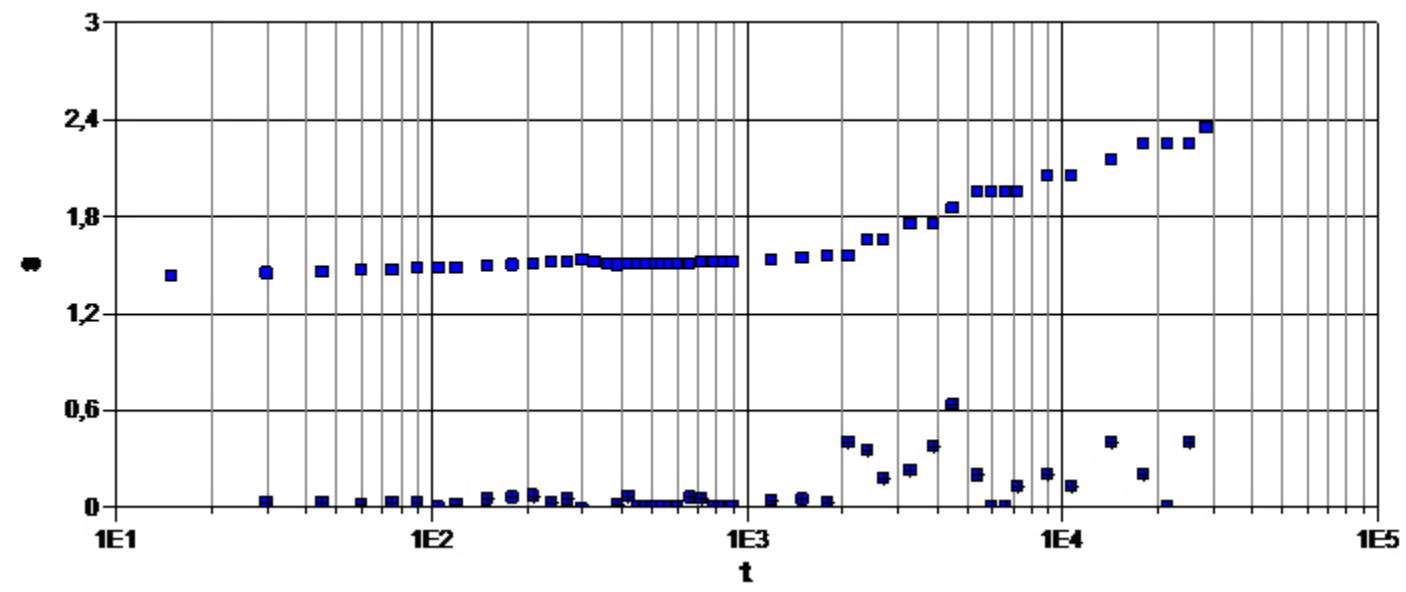

Figura 5. Comportamiento de abatimiento frente a tiempo para un acuífero libre, mediante la prueba de bombeo. Vereda Labrancitas, Paz de Ariporo.

Fuente: elaboración propia.

Estimation Plot: LABRANCITAS

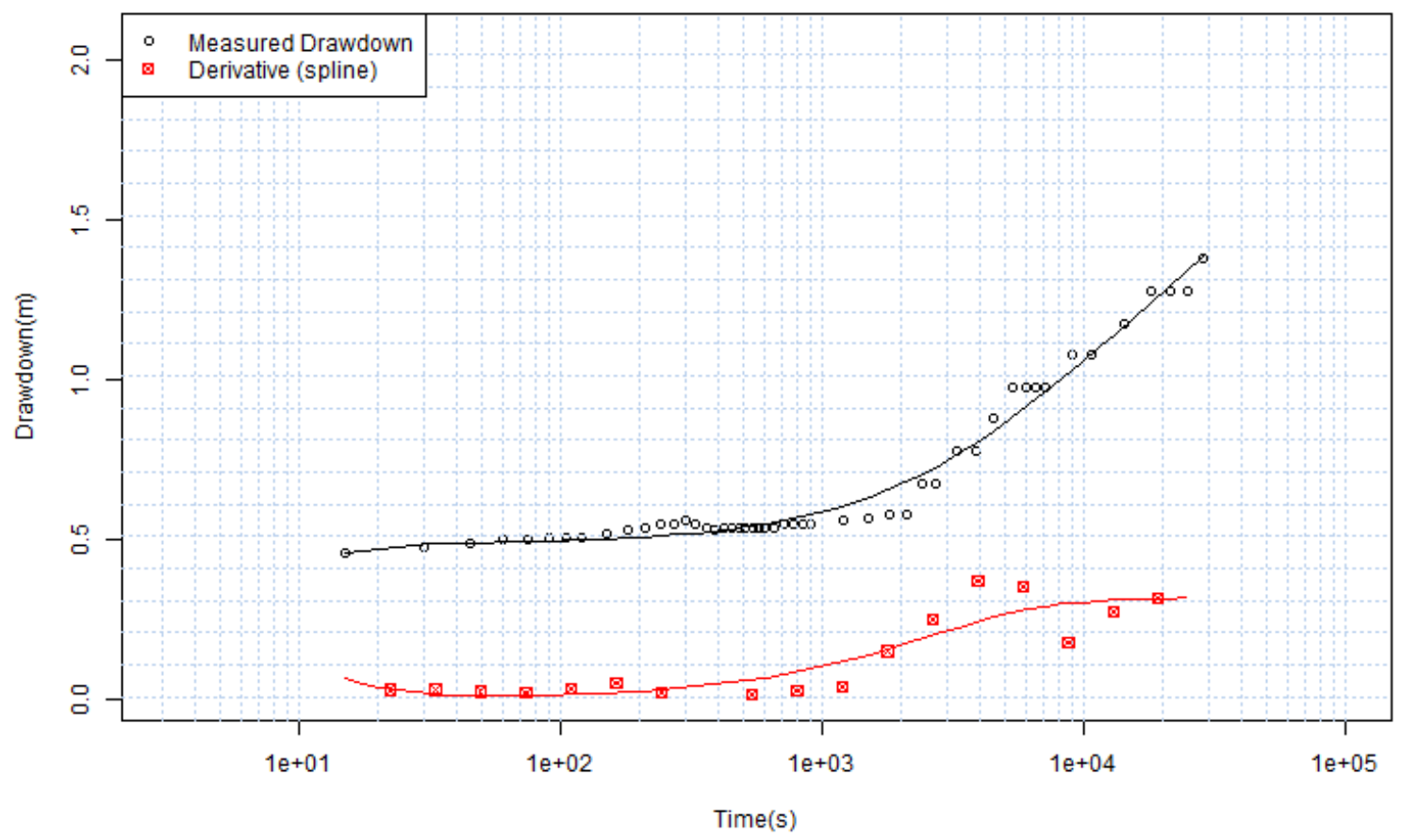

Figura 6. Abatimiento y su derivada frente a tiempo. Prueba de bombeo. Vereda Labrancitas, Paz de Ariporo. Fuente: elaboración propia. 
El método de Walton (basado en HantushJacob, 1955) [9] también asume acuíferos infinitos con filtración proporcional al abatimiento, donde los cambios del almacenamiento son despreciables y el flujo del agua en dirección del pozo es transitorio.

Finalmente, para acuíferos libres, se utilizó el método de Boulton (1954) [10], que se supone que la cantidad de agua derivada del almacenamiento dentro del acuífero no confinado consta del volumen de agua liberado instantáneamente del almacenamiento (el acuífero se comporta como confinado); y el rendimiento retardado, debido a un lento drenaje por gravedad.

En las cercanías a los sitios donde se realizaron las pruebas de pozo, se determinó la resistividad eléctrica de las rocas del subsuelo mediante un tomógrafo Abem Terrameter Ls 04-064-250, gracias al cual se realizaron cuatro tomografías, para conocer la litología de los acuíferos a profundidad, en distintos puntos, a lo largo de la única vía que conduce de Caño chiquito a Centro Gaitán (figura 7).

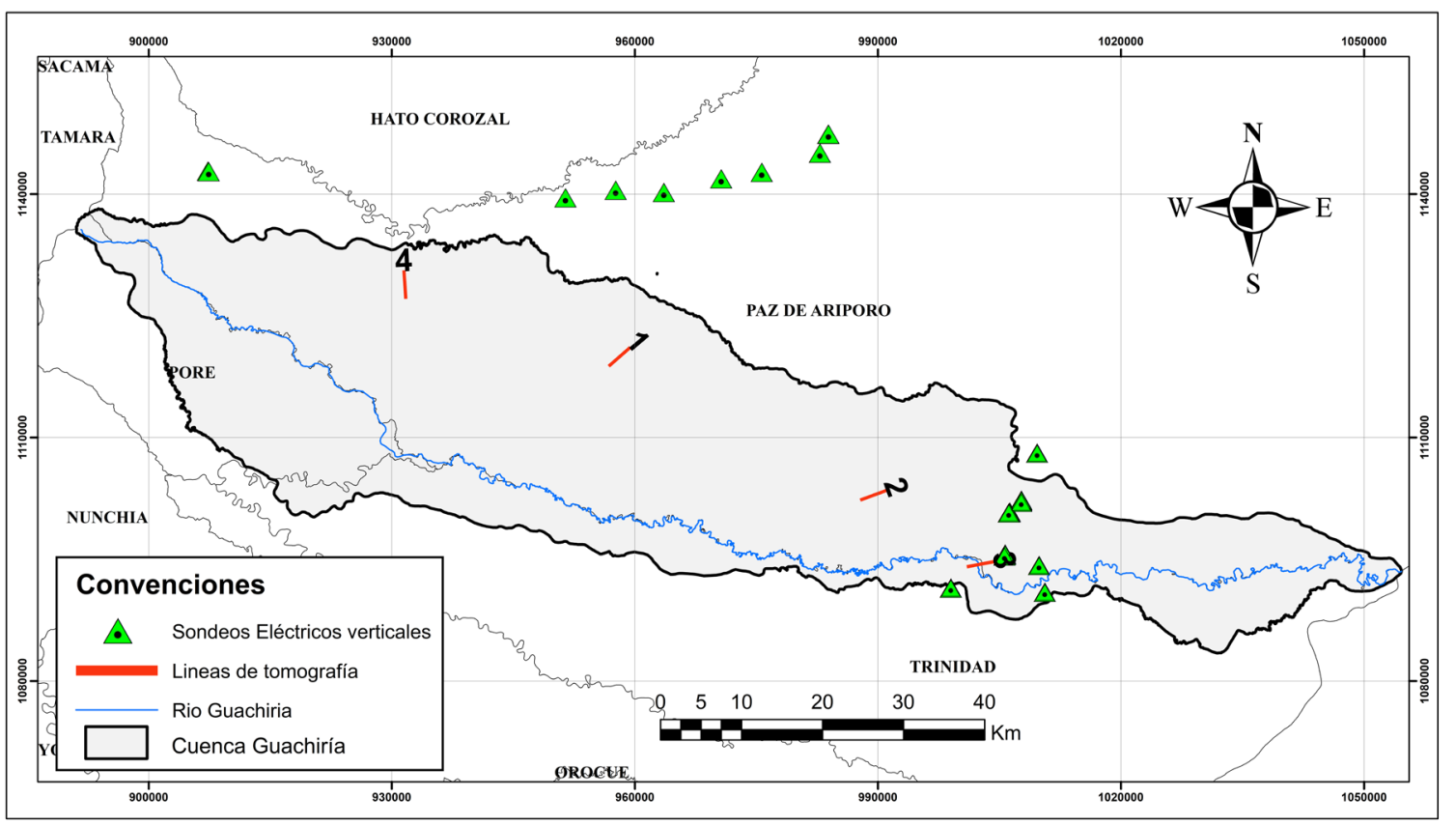

Figura 7. Localización de tomografías y SEV.

Fuente: elaboración propia.

El mencionado es un sistema avanzado de adquisición de imágenes topográficas para generar secciones o perfiles del subsuelo, con base en mediciones de caída de potencial eléctrico [11]. Ello permite correlacionar los resultados de los parámetros hidráulicos con la geología subsuperficial, subterránea y, así, corroborar la información obtenida.

A partir de las tomografías geoeléctricas, se obtiene una imagen de las propiedades eléctricas del subsuelo, para lo cual se hincan electrodos al suelo, separados a una misma distancia (10 metros para este caso a lo largo de una línea de perfil). Un cable multicanal conecta cada electrodo al sistema principal, que es el encargado de medir y almacenar la información, luego de inducir corriente eléctrica al subsuelo, donde se registra la caída de potencial eléctrico. Se realizó un arreglo tipo Schlumberger y la información obtenida fue procesada por medio del software RES2DIVN.

Además de estas tomografías, se recopiló información de Corporinoquía de varios SEV, divididos en tres grupos: unos, cercanos al piedemonte; otros, fuera del área de estudio en dirección $\mathrm{NE}$ cercano a la zona llamada montañas de Totumo; 
y otro grupo más, en la vereda de Centro Gaitán, en la sección más angosta de la cuenca, cuyo lineamiento atraviesa perpendicularmente a esta y al cauce principal del río Guachiría.

\section{Resultados y discusión}

\section{Interpretación de información geoeléctrica}

La hidráulica de la zona pudo correlacionarse con los estudios geoeléctricos que sirvieron de base para entender la geología subterránea y confirmar que los depósitos superficiales son preferencialmente arenosos, por su naturaleza eólica hacia la zona este de la cuenca de estudio (figura 8). A profundidad, se evidenció la presencia de areniscas, con intercalaciones de limos y arcillas, que corresponden al miembro superior de la Formación Guayabo, considerada un acuífero de mediana productividad [4], que se encuentra infrayaciendo a los acuíferos de depósitos cuaternarios superficiales. Este acuífero se comporta como un acuífero confinado a semiconfinado, debido a la alternancia y heterogeneidad de los depósitos superficiales.

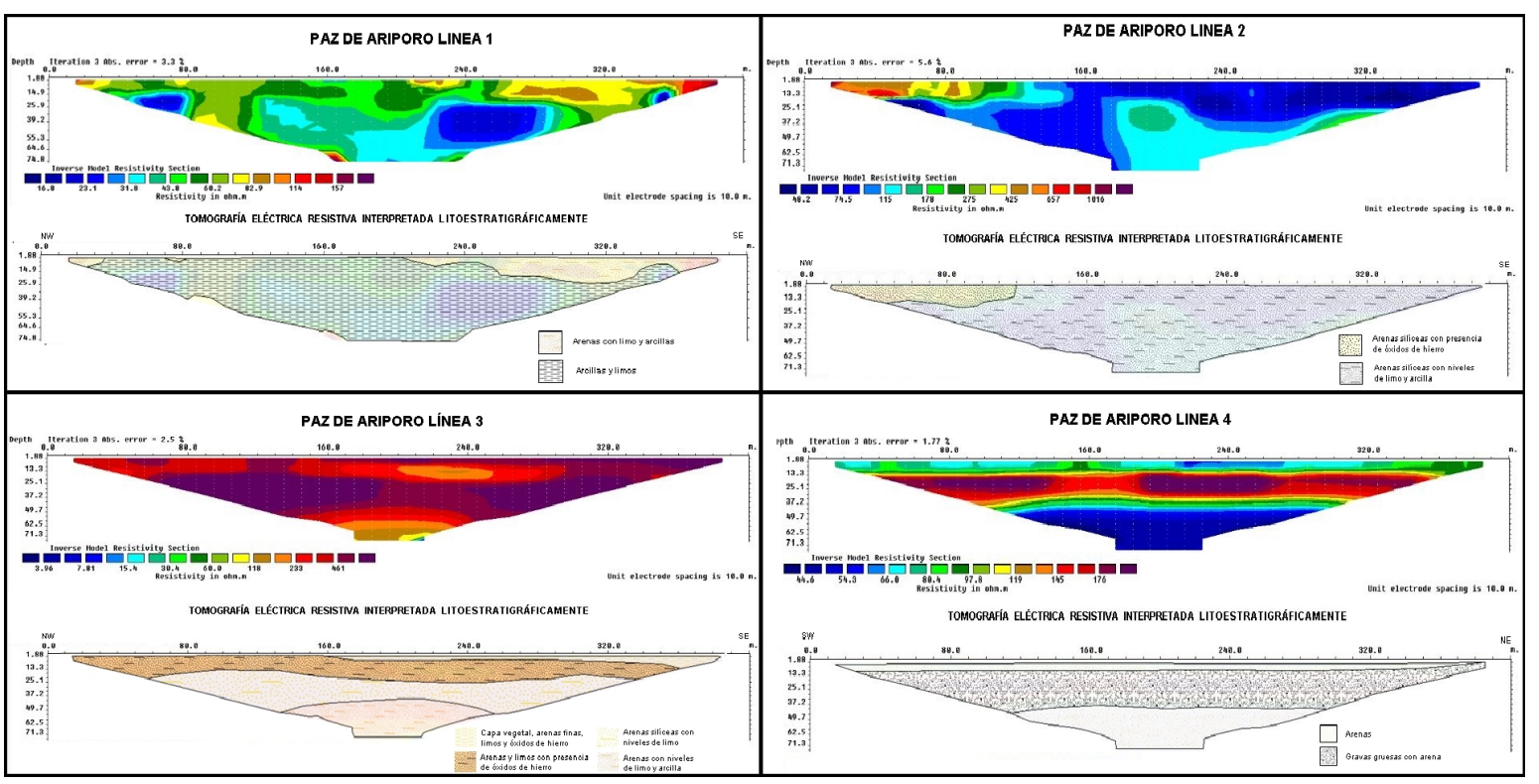

Figura 8. Líneas de tomografías e interpretación en Paz de Ariporo.

Fuente: elaboración propia.

Según la distribución de las tomografías en cuatro puntos de la cuenca, pudo observarse que (1), en la zona media, hay mayor presencia de finos -tomografías 1 y 2-; (2) el material arcilloso se representa con los colores azules y en tonos verdes claro, cuyos rangos de resistividad van de 16 a 43,8 $\Omega \times \mathrm{m}$, respectivamente, los cuales alcanzan espesores de hasta 74 metros y superiores, puesto que se tiene información geoeléctrica hasta esa cota; y (3) estas zonas corresponden también a las zonas de desborde de los ríos que pueden ser tenidos en cuenta como acuitardos, debido a la presencia de alto contenido de finos.

En la zona más alejada del piedemonte, donde los sondeos alcanzan a llegar a la roca, debido a una reducción de espesor de los depósitos cuaternarios, como muestra la tomografía 2, se encuentra presencia de limo y arcilla, identificadas con los colores azules y aguamarina, muy posiblemente por poseer una matriz arcillo-limosa. 


\section{Interpretación de parámetros hidráulicos}

Como resultado de la interpretación geológicogeofísica y de las pruebas de bombeo, se identificó que, por un lado, en trece de los pozos se bombea agua de depósitos de planicie aluvial y eólicos; y, por otro, en siete de ellos se bombea de la Formación Guayabo (tablas 1-3).

Para facilitar su análisis, los acuíferos se agruparon así: libres, semiconfinados y confinados. Además, teniendo en cuenta la gráfica de abatimiento frente a tiempo y los parámetros obtenidos de las pruebas, como el coeficiente de almacenamiento (S) que indica el agua liberada, al disminuir la presión de un acuífero confinado, y se determina mediante el cociente entre el volumen de agua liberado y el volumen total que ha bajado la superficie piezométrica (porosidad eficaz para acuíferos libres, Sy), se concluyó que, en total, hay cuatro pozos presentes en acuíferos libres, cinco en semiconfinados y siete en confinados (los cuatro pozos restantes obtenidos de la información previa o recopilada no se encuentran clasificados).

Por otro lado, los pozos se catalogaron de mediana a muy baja productividad, a partir de su capacidad específica. Los valores de transmisividades variaron de acuerdo con la facilidad de cada acuífero de ceder agua, cuyos valores oscilan entre 3,98 y $279 \mathrm{~m}^{2} /$ día. Aquí, las mejores transmisividades se encuentran en la vereda de Centro Gaitán en el pozo Dorotea A1 (tablas 1-3). Los caudales utilizados para las pruebas de bombeo varían entre 0,42 y $5,21 / s$, realizados por aforos volumétricos a medida que se bombeaban los pozos.

Los parámetros hidráulicos más relevantes para determinar las características de los acuíferos son (1) transmisividad, (2) conductividad hidráulica y (3) capacidad especifica. A continuación, se describen y analizan los resultados de cada una de las constantes hidráulicas encontradas en este estudio.

La transmisividad (T), que representa la capacidad de un acuífero para ceder agua, expresa la relación entre la conductividad hidráulica y el espesor del acuífero ( $T=K \times b$, donde $K$ es la conductividad hidráulica y $b$ el espesor del acuífero). Esta variable puede verse influenciada por los ambientes de depositación ocurridos en la zona, ya que a lo largo de toda la cuenca no son uniformes, por el permanente desplazamiento de los cauces, el régimen cambiante de depositación y la erosión de los canales. Estos procesos crean capas y barreras impermeables que impiden el libre flujo de agua subterránea por los depósitos permeables y cambian los espesores de los acuíferos, los cuales fluctúan entre 15 y 80 metros, aproximadamente.

Para los acuíferos confinados, la transmisividad fluctúa entre 70 y $280 \mathrm{~m}^{2} /$ día, lo que indica que, por un lado, son acuíferos de productividad pobre a regular o buena [14] y, por otro, están influenciados por arenas finas a limosas, junto con los acuíferos libres con transmisividades de 50-190 $\mathrm{m}^{2} /$ día. Para los acuíferos semiconfinados, la transmisividad fluctúa entre 4 y $130 \mathrm{~m}^{2} /$ día, lo que indica que son de productividad muy pobre a regular, donde los materiales limoarcillosos y arenolimosos limitan el libre movimiento del agua (tablas 1-3). La figura 9 permite ver que las mejores transmisividades coinciden con los depósitos eólicos que afloran hacia el oriente en las cercanías a la vereda Centro Gaitán [15].

La conductividad hidráulica es un indicador de la velocidad de desplazamiento de los fluidos, a través de las rocas y es directamente proporcional a la textura de granos que componen la roca. Los valores de conductividad hidráulica fluctuaron de 0,05 a $10 \mathrm{~m} /$ día, lo que los clasifica como rocas de muy baja a baja velocidad de movimiento del agua, a través de la estructura de la roca.

Los valores de conductividad hidráulica más altos se encontraron en el pozo Dorotea A1, (figura 10). A pesar de eso, dichas permeabilidades se encuentran clasificadas de medias a bajas, donde el flujo del agua es regular (tablas 1-3), esto debido a posibles intercalaciones de materiales finos influenciados por los depósitos eólicos. 


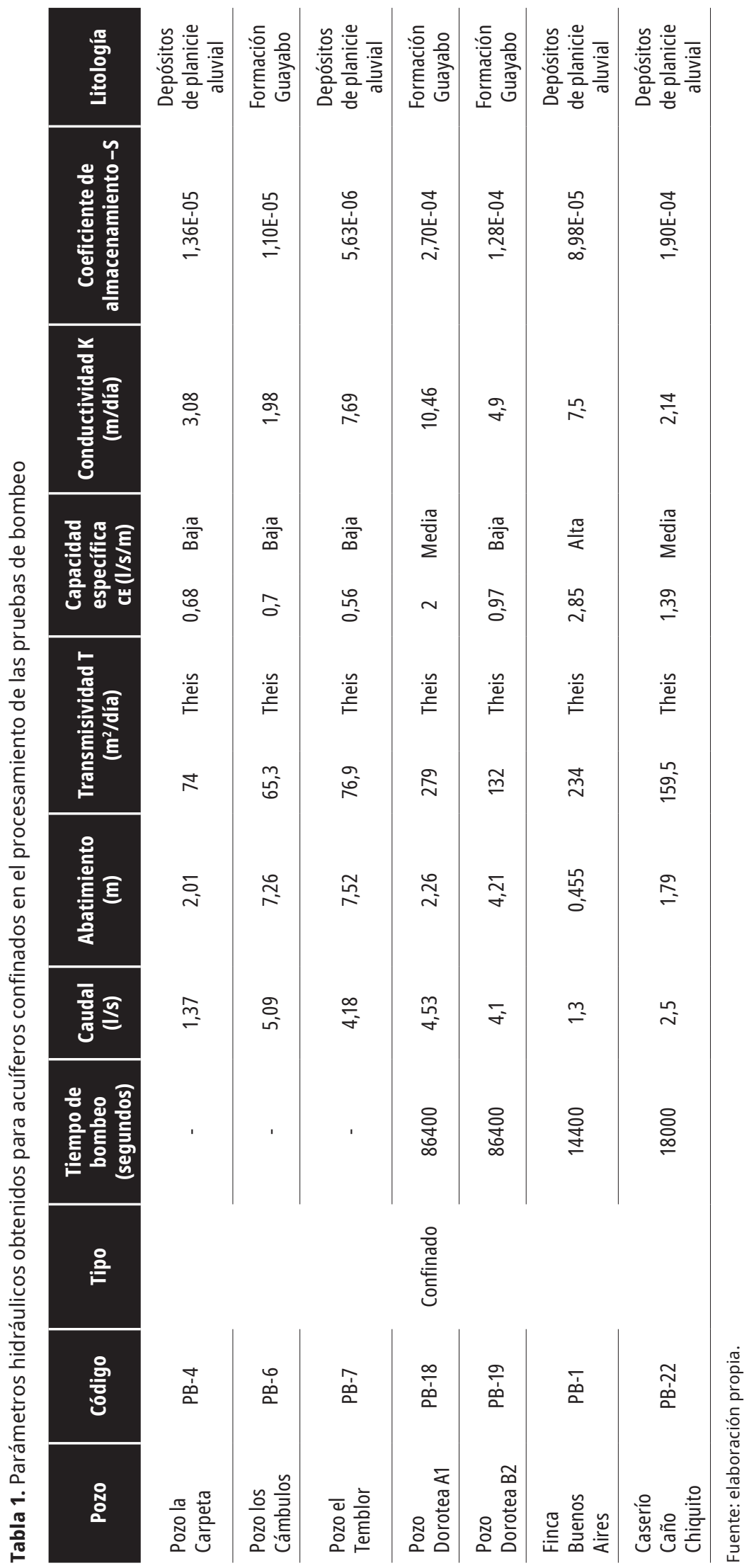



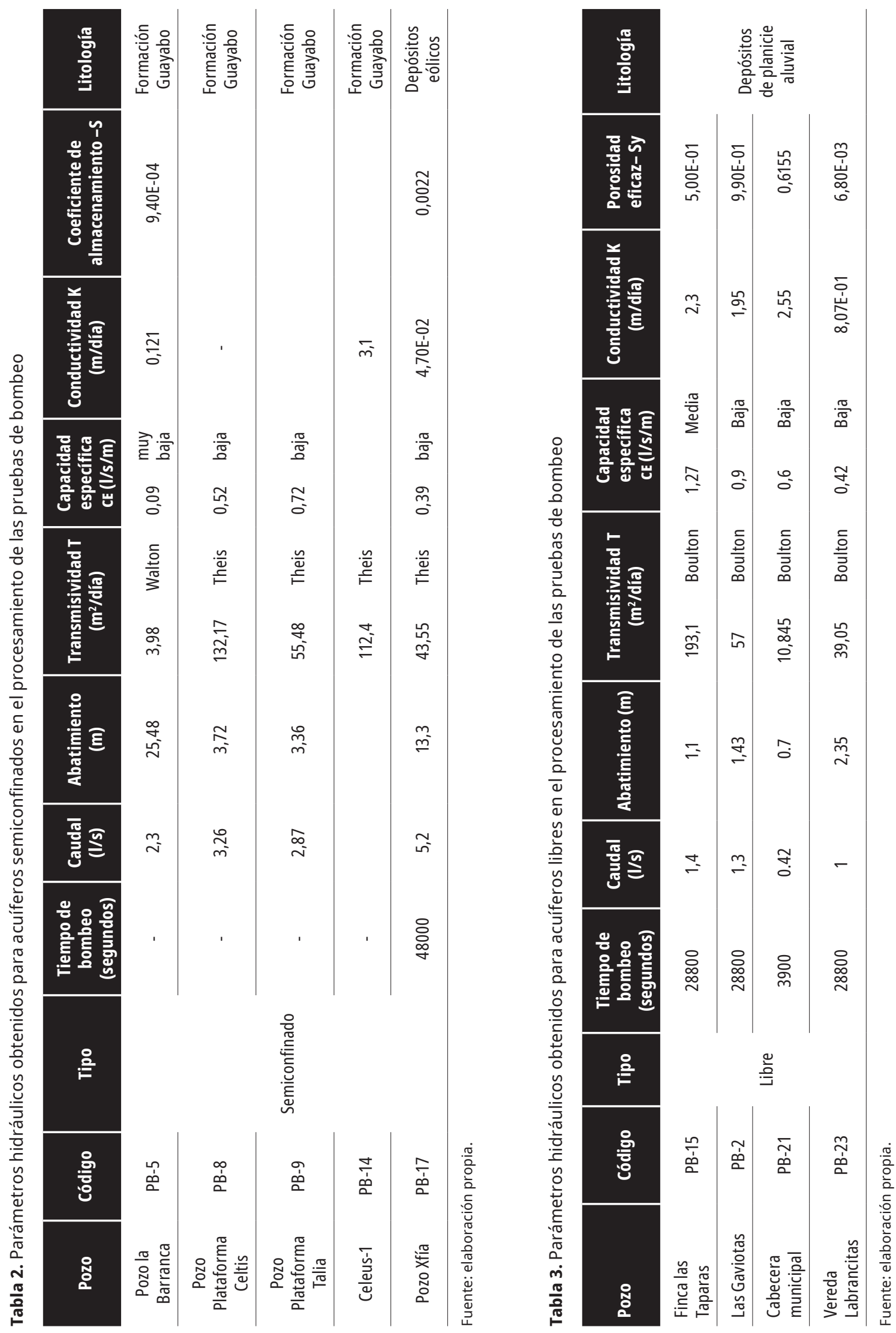


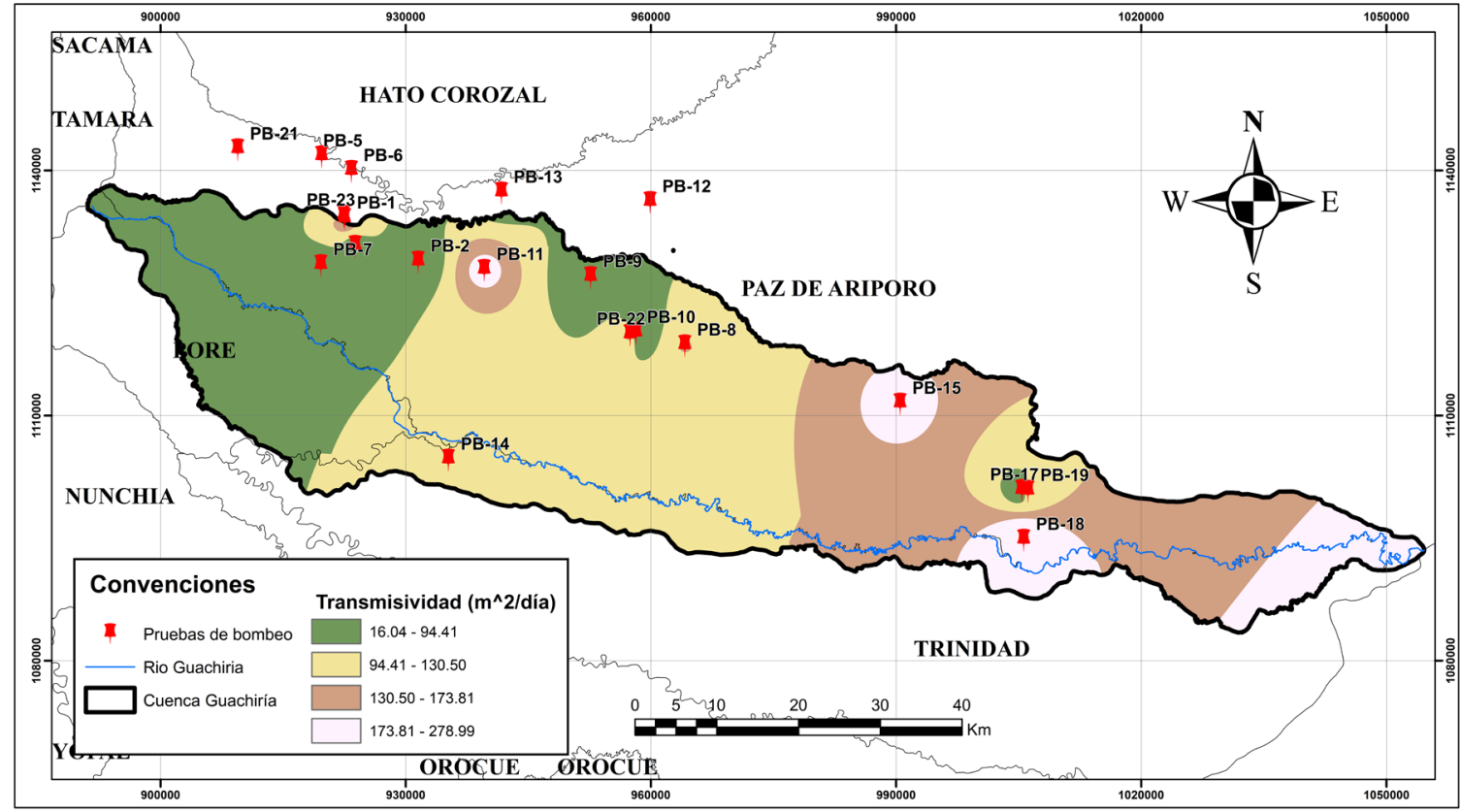

Figura 9. Mapa de transmisividades en la cuenca del río Guachiría.

Fuente: elaboración propia.

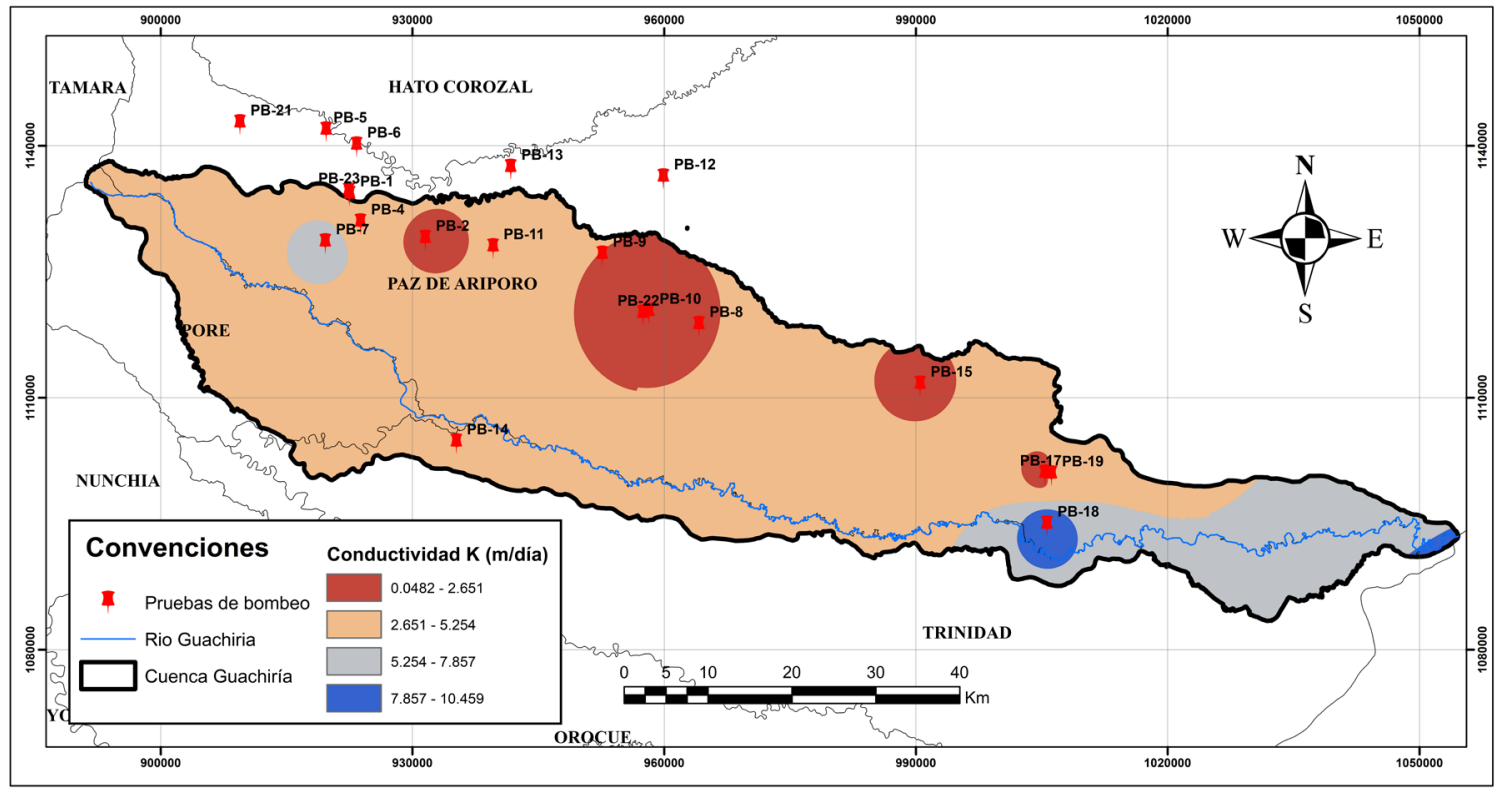

Figura 10. Mapa de conductividad hidráulica.

Fuente: elaboración propia. 
La capacidad especifica (CE), que es sinónimo de la productividad, en los diferentes acuíferos fluctuó entre 0,1 y $3 \mathrm{l} / \mathrm{s} / \mathrm{m}$, lo que los clasifica entre productividad baja y media. De acuerdo con su CE:

1) Quince pozos se encuentran ubicados en acuíferos continuos de extensión local y baja productividad, con valores que varían desde 0,425 a $1,3 \mathrm{l} / \mathrm{s} / \mathrm{m}$.

2) Tres pozos están en acuíferos continuos y discontinuos de extensión regional y mediana productividad con valores de CE desde 1,27 a $2,0 \mathrm{l} / \mathrm{s} / \mathrm{m}$.

3) Dos pozos se encuentran en acuíferos continuos y discontinuos de extensión regional, de alta productividad con valores de CE que van desde 2,8 y $3,1 \mathrm{l} / \mathrm{s} / \mathrm{m}$.

Estos valores varían de acuerdo con su espesor y continuidad, ya que las formaciones y depósitos son de grandes dimensiones y abarcan extensas zonas fuera de la cuenca.

Relacionando los acuíferos con la interpretación geológica-geofísica se dedujo que las litologías predominantes en el sector cercano al piedemonte y en la región más externa de la cuenca (tomografías 3 y 4) son arenas y gravas gruesas, que corresponden a los colores amarillos oscuros, rojos y morados en las tomografías con rangos de resistividad entre $119 \Omega \times \mathrm{m}, 6,61 \Omega \times \mathrm{m}$ y de más de $615 \Omega \times \mathrm{m}$, respectivamente.

En la tomografía 4, la más cercana al piedemonte, se observa claramente un mayor porcentaje de materiales detríticos y gravas a lo largo de toda la sección capa que presenta un espesor aproximado de 25 metros, cuya litología, sin embargo, no es un acuífero excelente, ya que existen intercalaciones de secuencias areno-limosas, y arcillas, ya que, observando sus valores de resistividad por el orden de 92-195 $\Omega \times$ m, puede catalogarse como un acuífero de mediana productividad (figura 8).

La región de la Orinoquia es una depresión estructural con dirección NE que comprende tres unidades estructurales: (1) el cinturón plegado localizado en el piedemonte (figura 11); (2) la depresión subandina (figura 12); (3) zona de mayor depositación sedimentaria y la plataforma o zona más distal relativamente estable (figura 13); y (4) zonas que presentan tres tipos de condiciones, que ejemplifican el comportamiento hidráulico de la cuenca del río Guachiría que, a lo largo del recorrido del cauce principal, sumadas a las condiciones hidrogeológicas e hidrológicas, determinan la ocurrencia del agua subterránea en esta región septentrional de los llanos orientales.

Las variaciones en transmisividad a lo largo de los depósitos cuaternarios y la Formación Guayabo se ven influenciadas por (1) la composición litológica variada y (2) la mezcla de litologías gruesas de los canales aluviales y (3) cuerpos arcillosos dejados por los cauces abandonados que conforman los acuíferos bombeados.

De acuerdo con la correlación entre la reinterpretación geofísica y la hidráulica de la zona estudiada, se determinó que la dinámica del río influenció en la depositación de materiales a lo largo del tiempo, modelando los acuíferos, afectando las propiedades hidráulicas al depositar cuerpos arenosos, limitados con barras de depósitos finos de meandros abandonados o zonas de inundación que ocasionalmente podrían convertir acuíferos libres en acuíferos confinados o semiconfinados, disminuyendo las propiedades de conductividad y almacenamiento de agua.

En cuanto a la extensión local y regional de los acuíferos, se ve influenciada de acuerdo con los diferentes eventos deposicionales ocurridas a lo largo de la historia geológica en los Llanos Orientales, donde están los acuíferos de interés, como los depósitos cuaternarios y la Formación Guayabo. 


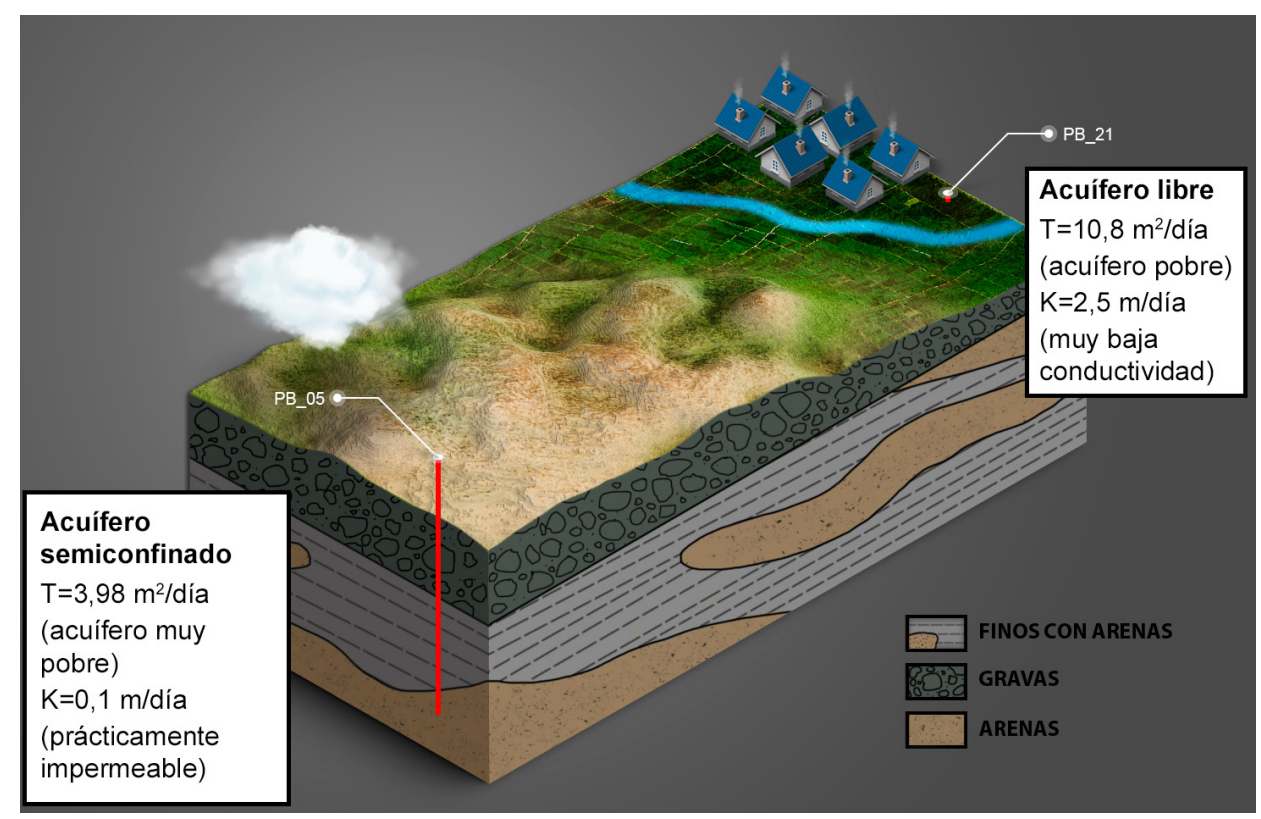

Figura 11. Esquema de un modelo hidrogeológico conceptual del piedemonte cercano al casco urbano de Paz de Ariporo. Se observan secuencias de gravas con arenas intercaladas con capas arcillosas confinantes, provenientes posiblemente de la Cordillera Oriental; presentan una disminución del espesor, a medida que se aleja del piedemonte. Esto podría deberse a una secuencia típica de un abanico aluvial donde la topografía y el tamaño de grano disminuyen a medida que se aleja del piedemonte.

Fuente: elaboración propia.

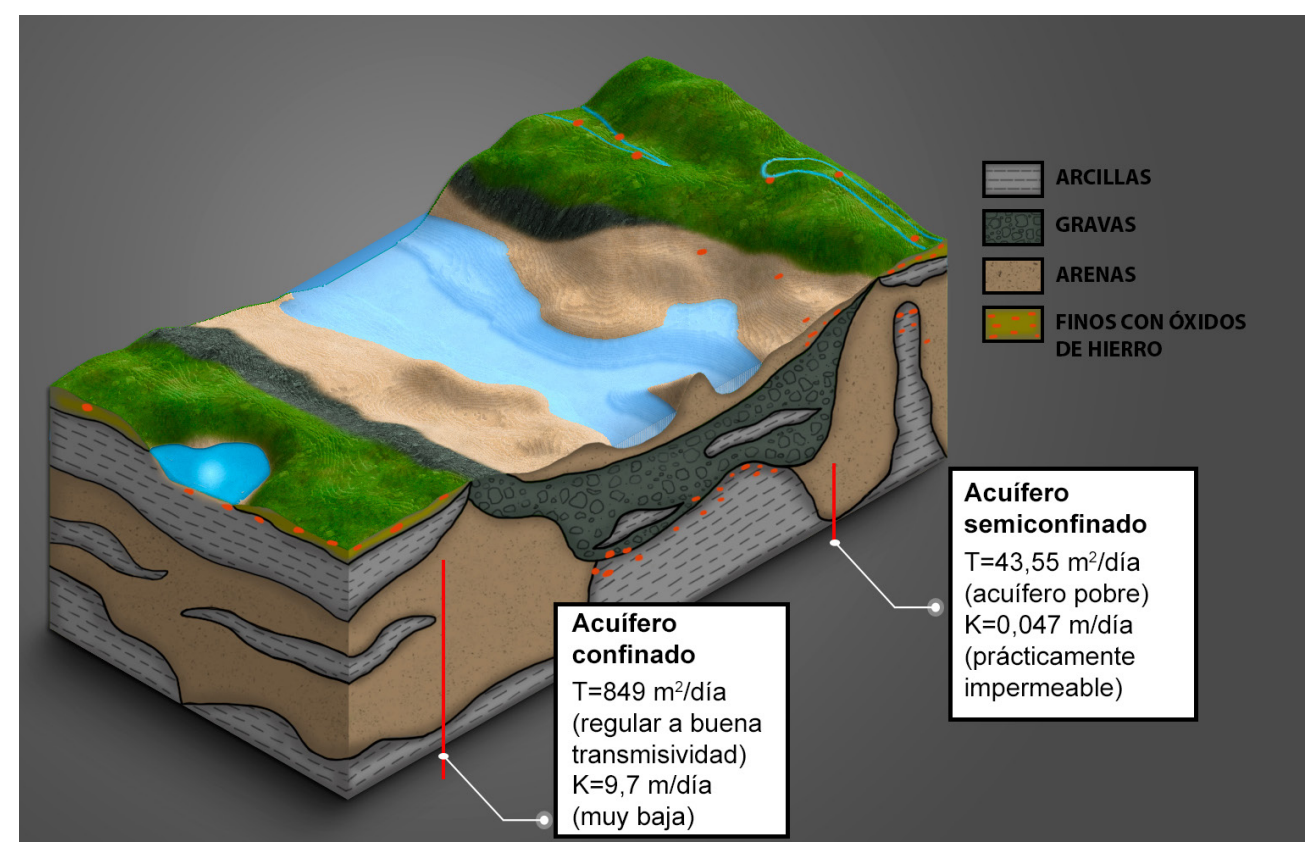

Figura 12. Modelo hidrogeológico conceptual de la región central de la cuenca, donde la influencia del canal central depositó barras de arenas y depósitos de canal intercalados con capas confinantes.

Fuente: elaboración propia. 


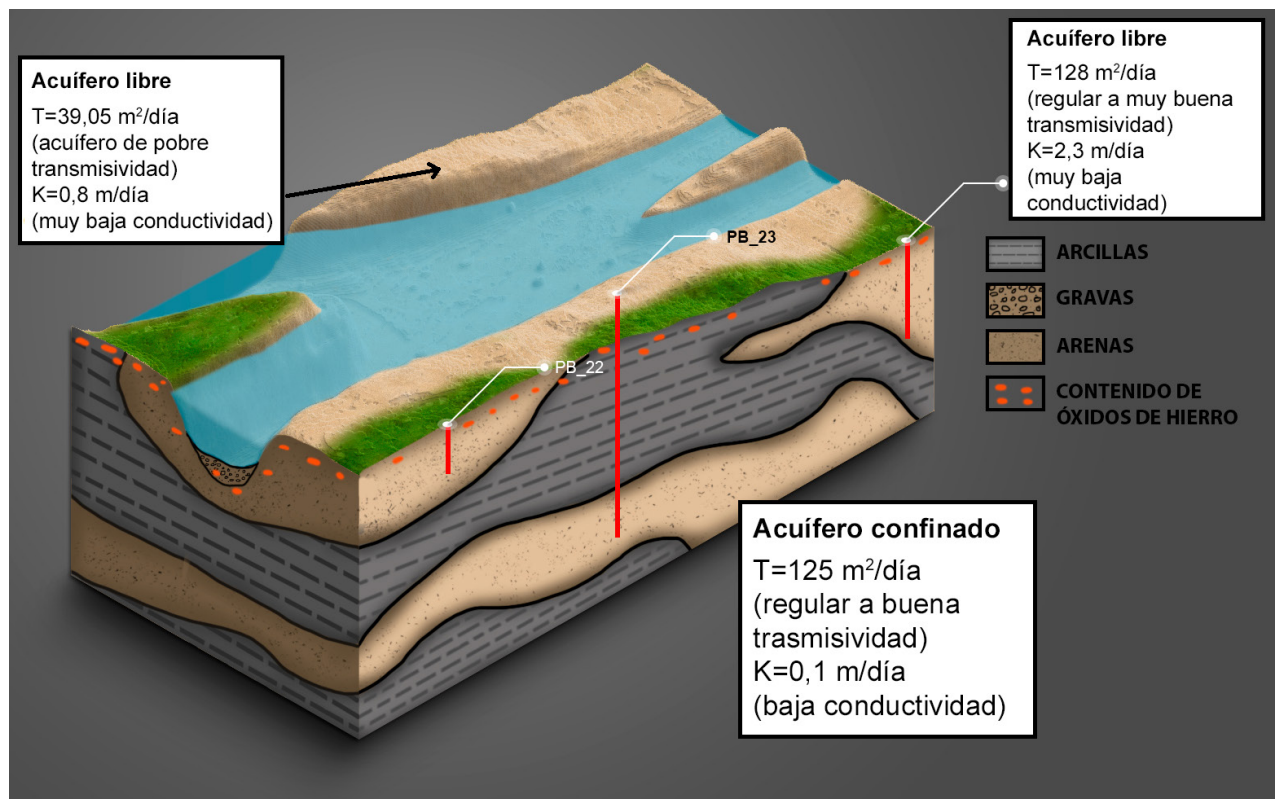

Figura 13. Modelo hidrogeológico conceptual de la zona más distal o llanura inundable, donde se presentan cuerpos arcillosos producto de las llanuras de inundación, cuerpos eólicos y canales abandonados. El cambio del nivel freático cercano a la superficie propicia la formación de costras de hierro, producto de la descomposición de los suelos y rocas ayudado por la intervención antrópica.

Fuente: elaboración propia.

\section{Conclusiones}

De acuerdo con las pruebas de pozos realizadas, los valores de transmisividad se encontraron en el rango 3,98-279 m²/día, por lo que los acuíferos se clasifican de productividades muy pobres a buenas. Esto está influenciado por los diferentes materiales depositados en los procesos denudativos en el ciclo evolutivo de los Llanos Orientales.

Se concluyó que, según la CE encontrada de 0,09-2,85 l/s/m, los acuíferos presentes en la zona son de productividad media y varían en su extensión y continuidad. Además, se trata de acuíferos que van de locales (depósitos cuaternarios) a regionales (Formación Guayabo), con variada productividad de muy baja a alta. A pesar de las diferentes características hidráulicas y su extensión, estas fuentes pueden dar abasto a la escasa población.

El conocimiento de las variables hidráulicas en la sabana estacional da una idea acerca de las zonas con las mejores condiciones, para la circulación del agua subterránea, especialmente hacia la región este, donde se encuentra la Formación Guayabo, cubierta por depósitos eólicos. Sin embargo, son valores ligados al conocimiento detallado de la geología, la información detallada de los pozos y, al no contar con estos datos debe, entenderse que existe cierta incertidumbre en la información.

Con el fin de disminuir tal incertidumbre, es recomendable poseer pozos de control o piezómetros para validar y dar confiabilidad a parámetros como el coeficiente de almacenamiento. De igual forma, permite conocer la estratigrafía del acuífero y sus espesores, puesto que de este factor depende la transmisividad, variable que sirven para estimar de la productividad del acuífero a estudiar.

La extensión de los acuíferos puede variar, ya que se encuentran ubicados en depósitos cuaternarios de grandes extensiones que, morfométricamente, se encuentran situados sobre superficies de planicie, influenciados por acuíferos aledaños.

Los materiales arcillosos corresponden también a las zonas de desborde de los ríos, y pueden ser tenidos en cuenta como acuitardos. Al 
contrarrestarse con los indicadores de productividad de las pruebas de bombeo en estas zonas, se confirmó que la productividad de estos acuíferos es baja.

De acuerdo con la correlación entre la reinterpretación geofísica e hidráulica de la zona estudiada, se determinó que la dinámica de los ríos influenció en la depositación de materiales. Esto modela los acuíferos y retrabaja depósitos eólicos, lo que afecta las propiedades hidráulicas, al depositar cuerpos arenosos limitados con barras de depósitos finos de meandros abandonados, o zonas de inundación que, ocasionalmente, podrían convertir acuíferos libres en acuíferos confinados o semiconfinados. En consecuencia, disminuyen las propiedades de conductividad y almacenamiento de agua.

Es recomendable que, para futuros proyectos agroindustriales en la zona de los Llanos Orientales, las fuentes de abastecimiento sean las formaciones de mayor profundidad como la Formación Guayabo, ya que no son tan vulnerables a las temporadas de estiaje, como los acuíferos superficiales, al momento de la extracción debe respetarse la capacidad de producción de cada uno de los acuíferos.

\section{Referencias}

[1] M. Guzmán, “'Donde se entrelazan dos mundos'. Más de una razón”, Revista Semana, pp. 34-35, 2015.

[2] Sistema Geológico Colombiano -SGC, Memoria Geológica de la Plancha 196. Río Guachiría. Bogotá: autor. Disponible en http://recordcenter. sgc.gov.co/B14/23008010024636/Documento/ PDF/2105246361101000.pdf

[3] H. González, et al. "Plancha 174- Paz de Ariporo", 2015, $79 \mathrm{pp}$.

[4] Alcaldía Municipal de Paz de Ariporo, "Plan Básico de Ordenamiento Territorial de Paz de Ariporo - вот (2011)", Casanare. Alcaldía municipal de Paz de Ariporo.

[5] Sistema Geológico Colombiano -sGC, Modelo hidrogeológico conceptual del municipio de Yopal, departamento de Casanare. Grupo de exploración de Aguas subterráneas. Bogotá: autor, 2018.
[6] C. Mora-Fernández, L. Peñuela-Recio, F. Castro-Lima. "Estado del conocimiento de los ecosistemas de las sabanas inundables en la Orinoquia Colombiana”, Revista Orinoquia, vol. 19, n. ${ }^{\circ}$ 2, pp. 253-271, 2015.

[7] G. P. Kruseman y N. A. de Ridder, Analysis and Evaluation of Pumping Test Data. Wageningen: Intern. Inst. for Land Reclamation and Improvements, 1994.

[8] C. Theis, "The Relation between the Lowering of the Piezometric Surface and the Rate and duration of Discharge of a Well Using Groundwater Storage", Transactions of the American Geophysical Union, vol. 15, n. 2 , pp. 519-524, 1935. Doi: https://doi.org/10.1029/ TR016i002p00519

[9] M. Hantush, "Nonsteady Radial Flow in an Infinite Leaky Aquifer", Transactions of the American Geophysical Union, vol. 36, n. ${ }^{\circ}$ 1, pp. 95-100, 1955. Doi: https:// doi.org/10.1029/TR036i001p00095

[10] N. Boulton, "The Drawdown of the Water-Table Under Non-steady Conditions Near a Pumped Well in an Unconfined Formation", Proceedings of the Institution of Civil Engineers, vol. 3, n. ${ }^{\circ} 4$, pp. 564-579, 1954. Doi: https://doi.org/10.1680/ipeds.1954.12586

[11] C. López y J. Mariño, Modelo hidrogeológico conceptual e isotópico de la sabana estacional de Paz de Ariporo, Casanare, Colombia. Anexo D. Tomografías geoeléctricas. Proyecto de investigación UPTC-Colciencias N. 005-2016, 2016.

[12] C. Benavides y L. Caro, Análisis hidrológico de la cuenca del río Guachiría (Casanare), asociado a parámetros hidráulicos, tesis inédita de pregrado, Departamento de Ingeniería Geológica, UPTC, Sogamoso, Colombia, 2019.

[13] J. Mariño, “Determinación del origen de la recarga en las sabanas de la Orinoquia colombiana a partir de isótopos”, XIV Congreso Latinoamericano de Hidrogeología, Argentina, 2018.

[14] W. Pérez, Clasificación de acuíferos mediante la determinación de parámetros hidráulicos en el abanico aluvial de Ibagué Tolima, tesis inédita de pregrado, Departamento de Ingeniería Geológica, UPTC, Sogamoso, Colombia, 2016.

[15] H. Chaparro, J. Mariño y H. Fonseca "Valores de permeabilidad en sabanas susceptibles a sequía en Paz de Ariporo, Casanare (Colombia)", Revista Orinoquia Ciencia y Sociedad, vol. 3, n. . 29, pp. 9-13, 2019. 